there is no trespass without wilful damage, and a little Ausflug can be wholly innocuous. Such a venture is rendered attractive by what Dr. Ewing has to say about art, or rather about works of art. 'Right' and 'harmonious' are words applicable to composition and balance; it is possible perhaps to go further and to assert that any "merely [my italics] rational analysis" is wholly incapable of adequate discernment in matters of æesthetic fittingness. The interesting thing is, however, that this is precisely the upshot, in analytic form, of Ruskin's lovely passage in his "Law of Help" ("Modern Painters", vol. 5), wherein he stakes his all upon composition as an individual achievement. Without it there is no picture; it is the creation of that artist, and of nobody else.

All these meditations may serve to show how rich in content is "The Definition of Good", and more, how valuable in suggestiveness. The historical pattern of ethical thought is present throughout as an unobtrusive background against which the author hangs his own definition, set off in a delicate frame. Yet he will not expect a crowd to be there gazing at it ; in a better world there might be,

"But knowledge to their eyes her ample page

Rich with the spoils of time did ne'er unroll. . .."

F. I. G. RAwLINS

\section{OPERATIONAL CALCULUS AND ITS APPLICATIONS}

\section{Modern Operational Calculus}

With Applications in Technical Mathematies. By Dr. N. W. McLachlan. Pp. xiv +218. (London: Macmillan and Co., Ltd., 1948.) 21s. net.

$\mathrm{T}$ HIS book is intended as an introduction to operational calculus based upon the transform of $f(x)$ defined by

$$
\varphi(p)=p \int_{0}^{\infty} \exp (-p t) f(t) d t,
$$

that is to say, the Laplace transform multiplied by $p$. The function $\varphi(p)$ so defined is identical with what Heaviside called the operational form. The advantage of the present treatment over Heaviside's is that the theorems of operation can be placed upon an impeccable basis without the necessity for acts of faith. The contents are: 1, the Laplace transform; 2, rules of the operational calculus; 3 , solution of ordinary linear differential equations with constant coefficients ; 4, solution of partial linear differential equations with constant coefficients; 5, evaluation of integrals ; 6, derivation of Laplace transforms ; 7, Laplace transform for a finite interval ; impulses.

This last chapter is stimulating and makes accessible the theory of a method of outstanding importance. There are six appendixes concerning matters on which the reader should be more fully informed. These articles form what the author calls the "mathematical limit gauge". Indeed, a valuable feature of this work is the actual checking of the validity of operations, such as inverting the order of integrations, integration of infinite series, term-byterm differentiation and so on.

Although the book is intended for postgraduate engineers and technologists, it will be seen from the foregoing remarks that the presentation is more rigorous than is usual in this kind of work. This departure is greatly to be welcomed, for should a costly design be based upon intuitive reasoning and the reasoning prove false, the result may be disastrous.

This book will no doubt appeal to a wider class of readers than the author expects. It should certainly be regarded as indispensable by all engaged in the many branches of science in which the operational calculus, to which Dr. McLachlan has made important original contributions, is a powerful tool.

L. M. Milne-Thomson

\section{AN INTRODUCTION TO RADIO ENGINEERING}

\section{Essentials of Radio}

By Morris Slurzberg and William Osterheld. Pp. xii + 806. (New York and London: MeGraw-Hill Book Co., Inc., 1948.) 36s.

7 Ther HE object of this book, according to the preface, is to describe at an intermediate level the prin. ciples of operation of thermionic valves and their associated circuits. It is intended for students at technical institutes or for radio technicians wishing to improve their basic knowledge of the operation of radio and electronic equipment; and, while it deals primarily with the applications of valves and associated circuits to radio receivers and transmitters, it serves also to give a general background to other industrial applications of electronic techniques.

The book achieves its declared purpose very well. For this very reason, the serious engineering student proceeding to a university degree is not likely, however, to find it very useful. It is essentially a technician's rather than an engineer's text-book.

The reader is assumed to have an elementary knowledge of electricity and magnetism, the authors having wisely avoided the fault, all too common in books of this sort, of beginning their book with an elementary course on electricity and magnetism. The reader's knowledge is 'refreshed' at appropriate points by restating fundamental relations in elementary theory in an appropriate practical form. Though the purist will find something to complain of in many of these practical restatements, the class of reader for whom the book is primarily intended is not likely to suffer much on account of an occasional lack of rigour. The analogy between radio and coal supply in Chapter 1 seems rather unnatural, and is unlikely to add to the understanding of the subject.

In spite of the title, the book deals almost exclus. ively with equipment. Wave propagation, though briefly mentioned, is not dealt with adequately. The appendixes provide much useful reference data in a convenient form, although, of course, the symbols and terminology are American, as also is the biblio. graphy. From the point of view of the British reader, at least, the latter point is rather a pity since, though the field is necessarily not so large as the American, there are a number of British publications which could usefully have been included.

The book is excellently produced, as we have come to expect of books from these publishers, and the radio technician and others concerned with the operation and maintenance of electronic equipment will find it a useful general text- and reference-book. W. R. 